whom intravenous pyelography was performed (table II). The prevalence of silent urolithiasis in the general population is unknown. It is therefore uncertain if and to what degree the finding of recurrent microhaematuria in an asymptomatic young adult increases the probability of urolithiasis. Furthermore, the course of silent urolithiasis has not been studied. It is therefore uncertain whether the benefit of its early detection and management exceeds the morbidity, inconvenience, and cost of intravenous pyelography in 10 young adults in order to detect urolithiasis in one. We believe that until data on the prevalence and natural history of silent urolithiasis become available, persons aged 40 or less with asymptomatic microhaematuria should be followed up without invasive investigations. Furthermore, we would not recommend screening for haematuria in asymptomatic young men, since positive results do not justify further work up or treatment.

\section{References}

1 Greene LF, O'Shaughnessy EJ, Hendricks ED. Study of five hundred patients with asymptomatic microhematuria. $7 A M A$ 1956;161:610-3.

${ }^{2}$ Carson CC, Segura JW, Greene LF. Clinical importance of microhematuria. $f A M A$ 1979;241:149-50.

3 Golin AL, Howard RS. Asymptomatic microscopic hematuria. $f$ Urol 1980;124:389-91.

4 Burkholder GV, Dotin LN, Thomason WB, Beach PD. Unexplained hematuria. FAMA 1969;210:1729-33.

5 Harrison JH, Gittes RF, Perlmutter AD, Stamey TA, Walsh PC, eds. Campbell's urology. 4th ed. Philadelphia: W D Saunders Co, 1976.

- Wallace DM, Harris DL. Delay in treating bladder tumours. Lancet 1965 ;ii :332-4.

'Benson GS, Brewer ED. Hematuria: algorithms for diagnosis. $\mathcal{f} A M A$ $1981 ; 246$ : $993-5$.

8 Brenner BM, Rector FC, eds. The kidney. 2nd ed. Philadelphia: W D Saunders Co, 1981.
9 Gartman E. The significance of hematuria in young men. $f$ Urol 1956;75: 135-42.

${ }^{10}$ Anonymous. Undiagnosed haematuria [Editorial]. Br Med f 1975 ;i :647.

11 Ferris TF, Gordon P, Kashgarian M, Epstein FH. Recurrent hematuria and focal nephritis. $N$ Engl $f$ Med 1967;276:770-5.

12 Michael J, Jones NF, Davies DR, Tighe JR. Recurrent haematuria: role of renal biopsy and investigative morbidity. $\mathrm{Br} \mathrm{Med} \mathcal{F}$ 1976; : 686-8.

${ }^{13}$ Chen BTM, Ooi BS, Tan KK, Khoo OT. Causes of recurrent hethaturia. $Q \mathcal{F}$ Med 1972;41:141-8.

14 Paone DB, Meyer LE. The effect of biopsy on therapy in renal disease. Arch Intern Med $1981 ; 141: 1039-41$.

${ }^{15}$ Pardo V, Berian MG, Levi DF, Strauss J. Benign primary hematuria, Clinicopathologic study of 65 patients. Am F Med 1979;67:817-22.

16 Vehaskari VM, Rapola J, Koskimies O, Savilahti E, Vilska J, Hallman N. Microscopic hematuria in school children: epidemiology and clinicopathologic evaluation. $\mathcal{F}$ Pediatr 1979 ;95:676-84.

17 Dodge WF, West EF, Smith EH. Proteinuria and hematuria in schoolchildren: epidemiology and early natural history. $\mathcal{F}$ Pediatr 1976;88: $327-47$.

18 Silverberg E. Urologic cancer, statistical and epidemiologic information. New York: American Cancer Society, 1973.

19 Rofe P. The cells of notmal human urine. 7 Clin Pathol 1955;8:25.

${ }^{20}$ Kesson AM, Talbott JM, Gyory AZ. Microscopic examination of urine. Lancet 1978 ;ii :809-12.

${ }^{21}$ Sanders C. Clinical urine examination and incidence of microscopic haematuria in apparently normal males. Practitioner 1963;191:192-7.

22 Wright WT. Cell counts in urine. Arch Intern Med 1959;103:76-8.

${ }^{23}$ Larcom RC, Carter GH. Erythrocytes in urinary sediment: identification and normal limits. F Lab Clin Med 1948;33:875-80.

24 Free HM, Free AH, Giordana AS. Studies with a simple test for detection of occult blood in urine. $\mathcal{F}$ Urol 1956;75:743-52.

${ }^{25}$ Freni SC, Henderik GJ, Hol C. Centrifugation techniques and reagent strips in the assessment of microhaematuria. $\mathcal{F}$ Clin Pathol 1977;30: $336-40$.

${ }^{26}$ Bee DE, James GP, Paul KL. Hemoglobinuria and hematuria: accuracy and precision of laboratory diagnosis. Clin Chem 1979;25:1696-9.

27 Gadeholt $\mathbf{H}$. Quantitative estimation of urinary sediment with special regard to sources of error. $\mathrm{Br} \mathrm{Med} \mathcal{F} 1964 ; \mathrm{i}: 1547-50$.

(Accepted 13 October 1983)

\title{
Electroconvulsive therapy: results in depressive illness from the Leicestershire trial
}

\author{
S BRANDON, P COWLEY, C MCDONALD, P NEVILLE, R PALMER, S WELLSTOOD-EASON
}

\begin{abstract}
Electroconvulsive therapy was investigated in a double blind trial. Altogether 186 clinically selected patients were referred to the trial, but 48 of these did not participate. According to the present state examination, 95 of the remaining 138 patients fell into one of the classes of major depression. Patients were randomly allocated to a course of real or simulated electroconvulsive therapy. Treatment was given twice a week with a maximum of eight treatments. On the Hamilton depressive rating scale the improvement in the group given real treatment was significantly greater than that in the group given simulated treatment both at two weeks $(p=0.014)$ and at
\end{abstract}

\footnotetext{
Department of Psychiatry, University of Leicester, Leicester Royal Infirmary, PO Box 65, Leicester LE2 7LX

$S$ BRANDON, MD, FRCPSYCH, professor

P COWLEY, BMEDSCI, MRCPSYCH, lecturer

C MCDONALD, MA, research assistant

P NEVILLE, BM, MRCPSYCH, senior registrar

R PALMER, MB, MRCPSYCH, senior lecturer

$S$ WELLSTOOD-EASON, MRCS, LRCP, MRCPSYCH, lecturer

Correspondence to: Professor $S$ Brandon.
}

four weeks ( $p=0.0001)$. At follow up at 12 and 28 weeks there was no difference between the treatment groups. At the end of the four week trial consultants, who were blind to the allocation of treatment, rated the patients who had received real treatment as having made a significantly greater improvement than the patients who had received simulated treatment $(p<0.00005)$. Further analysis showed that electroconvulsive therapy was effective in depression associated with delusions and in depression associated with retardation.

\section{Introduction}

Although the Royal College of Psychiatrists was able in 1977 to say that the evidence in favour of electroconvulsive therapy in depressive states seemed incontrovertible, ${ }^{1}$ serious doubts continued to be expressed, not least by lay pressure groups, who in some : parts of the world achieved the abolition or serious restriction of this treatment. Lambourn and Gill in a double blind controlled trial compared unilateral brief pulse electroconvulsive therapy with simulated treatment and found no significant difference in outcome. ${ }^{2}$ Freeman et al undertook a study in which a control group received two "dummy" applications of electroconvulsive therapy before proceeding to a 
complete course and showed a greater improvement in the group given real treatment. ${ }^{3}$ Simultaneous use of antidepressant drugs and use of only two placebo treatments, however, made the results of this trial less certain.

The well designed and carefully controlled clinical trial conducted by the Medical Research Council at Northwick Park showed that electroconvulsive therapy had only a small effect in depression at the end of the trial period and there was no difference in the condition of patients given real and simulated treatment at one and six months of follow up. ${ }^{4}$ West, however, reported a double blind random allocation study in which electroconvulsive therapy was shown to be clearly superior to simulated treatment. ${ }^{5}$ The sample size (22 cases), the unusually unequivocal result (all patients given simulated treatment improved on crossover to real treatment), problems of selection, and doubts about the extent to which blindness was achieved failed to dispel the uncertainties. If the undoubted beneficial effects of electroconvulsive therapy were due to an elaborate placebo response the treatment would be comparable with insulin coma therapy, in which Ackner et al had shown that any effects were not due to the induction of coma with insulin. ${ }^{6}$ The absence of a specific antidepressant effect would provide a strong case for abandoning electroconvulsive treatment. Such a serious step demanded a further examination of the issue and provided ethical justification for a further double blind placebo controlled (simulated) trial of electroconvulsive therapy in depressive disorders, which we report here.

\section{Patients and methods}

We proposed to avoid bias in selection by including all patients for whom inpatient electroconvulsive therapy was prescribed from a total population of 840000 within Leicestershire. An initial research interview provided data on which diagnostic groupings could be established after entry into the trial. In this way an unbiased clinically selected group of patients with depression was obtained. All 28 consultants agreed to participate. Consultants retained overall clinical responsibility except while the patient was in the electroconvulsive therapy suite. Only inpatients were included as we did not think we could ensure adequate protection for patients on an outpatient basis. Retrospective analysis of usage of electroconvulsive therapy showed that there was little if any change in the rate of its prescription or the balance between inpatients and outpatients. Patients who required more than one course of electroconvulsive therapy during the trial period were not re-entered into the trial, and the number of subsequent sessions became an additional dependent variable.

Written consent to electroconvulsive therapy was obtained by the consultant in the usual way. A member of the research team then gave the patient oral and written information about the study and obtained separate written consent to enter the trial. Patients were excluded from the trial after initial assessment if they were receiving electroconvulsive therapy against their expressed wish, if poor command of English or other problems occasioned difficulty in obtaining fully informed consent, or if medical complications made placebo treatment unacceptable.

Full details on the patients were obtained by a member of the research team who was blind to their treatment. The initial interview included an extensive demographic record and a comprehensive rating package including the present state examination, ${ }^{7}$ comprehensive psychopathological rating scale, ${ }^{8}$ Montgomery Asberg depressive rating scale, ${ }^{9}$ Hamilton depressive rating scale, ${ }^{10}$ Newcastle depressive scale and electroconvulsive therapy index, ${ }^{11}$ observer and self rating visual analogue scales, ${ }^{12}$ Leeds Wakefield irritability depression anxiety scale, ${ }^{13}$ and Spielberger anxiety rating scale. ${ }^{14}$ Information was also collected about attitudes to treatment and recent life events. After the initial interview patients were assessed at weeks 2 and 4 during the trial and two months and six months after the final treatment. In addition, at weeks 1 and 3 observer and self rating visual analogue scales were completed.

After the initial assessment each patient was allocated a code number and regardless of diagnosis allocated according to previously determined random numbers to receive treatment or placebo (simulated treatment). Elaborate arrangements ensured that research and nursing staff had no opportunity to discover which group the patients were in. Treatment was carried out in "sealed off" electroconvulsive therapy units and administered by a member of the research team who had no access to any other information on the patient. Nurses and anaesthetists had no contact with the patients outside the electroconvulsive therapy suite and were "sworn to secrecy." Other nursing staff had no access to patients during or after treatment until the patient was able to enter the-recovery room. We could find no evidence of any breach of security.

In the treatment room all patients received a standard anaesthetic of methohexitone and suxamethonium at a dosage related to body weight ( $1 \mathrm{mg}$ methohexitone $/ \mathrm{kg}, 0.5 \mathrm{mg}$ suxamethonium $/ \mathrm{kg}$ ). No atropine was used, and oxygenation was maintained throughout. An Ectron Mark IV electroconvulsive therapy machine was used with bilateral temporal electrodes. The machine was used on setting 1 , which delivers a chopped sine wave discharge. For the treatment group the current was passed and the patient carefully observed to ensure that a bilateral fit took place. For patients in the placebo group the same procedure was followed but the current was not passed. A course comprised eight treatments usually given as two treatments weekly for four weeks. If the consultant thought that full recovery had occurred treatment could be stopped before the eighth treatment. Patients could be withdrawn by their consultant if their clinical condition was deteriorating and could withdraw themselves at any stage of the trial; after withdrawal they could then have "real" treatment if required. Any patient requiring more than the eight trial treatments subsequently received real treatment. If a patient received fewer than four trial treatments this was defined as constituting an incomplete course of treatment and the patient was excluded from further analysis.

During the four weeks of the trial no patient received antidepressant drugs but consultants were permitted to prescribe selected anxiolytics if they regarded this as necessary to patient care.

During the follow up period the confidentiality of which treatment had been given was maintained but consultants had a free choice of treatment methods. Although continued restriction of treatment choice would have been scientifically desirable, it was not regarded as being acceptable ethically or to the consultants concerned.

\section{Results}

Between June 1981 and February 1982, 219 inpatients started a course of electroconvulsive therapy and were eligible to enter the trial. Of the 186 who were interviewed by a member of the research team, 48 refused to participate in the trial. The reasons for non-participation were that they were receiving treatment against their wishes (nine patients); that they had faith in electroconvulsive therapy (eight); that there were problems of consent (for example, family disagreement) (13); personal (for example, expediency) (15); and others (for example, language problems) (three). The present state examination was used to divide the remaining 138 subjects into the computer derived catego classes as follows: depression with retardation 56 patients; depression with delusions 26; neurotic depression 13; and non-depressive diagnoses 43 . Thus 95 patients comprised the three main categories of depression.

Table I shows the demographic variables in the patients with depression. At the initial assessment the researcher judged, according to defined criteria, whether the patient had received an adequate course of antidepressant treatment before entering the trial. There were no significant differences between the treatment groups. Benzodiazepines were permitted as sedatives for the daytime and nighttime during the trial; the difference in distribution between the two groups was not significant.

Eighteen of the patients with depression failed to complete a full course of trial treatment: 16 were withdrawn from treatment during

TABLE I-Demographic variables in patients with depression

\begin{tabular}{lcc}
\hline & $\begin{array}{c}\text { Real ECT } \\
(\mathrm{n}=53)\end{array}$ & $\begin{array}{c}\text { Simulated ECT } \\
(\mathrm{n}=42)\end{array}$ \\
\hline $\begin{array}{l}\text { Mean age (years) } \\
\text { No (\%) of men }\end{array}$ & $55 \cdot 4$ & $53 \cdot 0$ \\
No (\%) of women & $21(40)$ & $13(31)$ \\
Mean No of previous admissions & $32(60)$ & $29(69)$ \\
$\begin{array}{l}\text { No (\%) of patients who had received ECT } \\
\text { before }\end{array}$ & $2 \cdot 6$ & $2 \cdot 5$ \\
$\begin{array}{l}\text { No of patients who had received adequate } \\
\text { course of antidepressants before trial }\end{array}$ & $29(55)$ & $28(65)$ \\
$\begin{array}{l}\text { Yes } \\
\text { Probably }\end{array}$ & $19(36)$ & $20(48)$ \\
No & $95(17)$ & $11(26)$ \\
\hline
\end{tabular}

ECT $=$ Electroconvulsive therapy. 
the four week trial period (table II), and two received fewer than four trial treatments and were excluded from the analysis. Both of these latter patients were in the group receiving simulated treatment. There was no significant difference in the number of patients in each treatment group who were withdrawn. Thus 77 patients with depression completed the four week trial period (table III).

TABLE II-Reasons for patients failing to complete course of treatment

\begin{tabular}{lccc}
\hline & $\begin{array}{c}\text { Real treatment } \\
(\mathrm{n}=53)\end{array}$ & $\begin{array}{c}\text { Simulated treatment } \\
(\mathbf{n}=\mathbf{4 2})\end{array}$ & $\begin{array}{c}\text { Total } \\
(\mathrm{n}=95)\end{array}$ \\
\hline $\begin{array}{l}\text { Physical health } \\
\text { Clinical deterioration }\end{array}$ & 1 & 3 & 1 \\
Self discharge & 1 & 5 & 4 \\
Consent withdrawn & 4 & 1 & 9 \\
Suicide & & 1 & 1 \\
\hline Total & 6 & 10 & 16 \\
\hline
\end{tabular}

TABLE III-Numbers of patients randomised to each treatment group by category of depression

\begin{tabular}{lccc}
\hline & Real treatment & Simulated treatment & Total \\
\hline $\begin{array}{l}\text { Depression with } \\
\text { delusions }\end{array}$ & 16 & 5 & 21 \\
$\begin{array}{l}\text { Depression with } \\
\text { retardation }\end{array}$ & 22 & 26 & 48 \\
Neurotic depression & 5 & 3 & 8 \\
\hline Total & 43 & 34 & 77 \\
\hline
\end{tabular}

The figure shows the outcome in terms of the scores on the Hamilton depressive rating scale in all 77 patients with depression who completed the trial. Overall the improvement at two and four weeks was significantly greater in the group given real treatment than in the group given simulated treatment. At 12 and 28 weeks substantial improvement had occurred in both groups and the differences were no longer significant. The subgroups of patients with retardation and with delusions showed the same pattern. In the subgroup with neurotic depression there were no significant differences between the treated and untreated groups at any assessment point, but this diagnostic category comprises only eight patients.

If the consultant considered that the patient had made sufficient clinical improvement trial treatment was stopped. Eleven patients out of $\mathbf{4 3}$ given real treatment received fewer than eight trial treatments for this reason compared with two out of 34 given simulated treatment; this difference was significant $(p=0.017$, Fisher's exact probability test). At the end of the four week trial period consultants were asked whether they thought the patient had received real or simulated treatment. The number of correct responses was no greater than chance. On a seven point scale of change in the patients' condition, however, they rated the patients who had received real treatment as having made a significantly greater improvement than the patients who had received simulated treatment. The mean rank for the 43 patients who received real treatment was 45.98 and that for 29 of the patients who received simulated treatment (consultants failed to complete the ratings on five patients) was 25.34 (Mann-Whitney $U=300.0$; two tailed $\mathrm{p}<0.00005$ ).

After the four week trial period consultants could prescribe a course of real electroconvulsive therapy following on from the trial treatments. Twenty of the 34 patients given simulated treatment subsequently had a continuous course of real treatment, compared with only 17 of the 43 patients given real treatment in the trial (Fisher's exact probability $p=0.04)$. Patients who received simulated treatment in the trial and subsequently had a continuous course of real treatment received a greater number of treatments per course $(6 \cdot 77)$ compared with patients who received real treatment in the trial $(5 \cdot 24)$.

\section{Discussion}

The present study shows a highly significant difference in outcome in favour of real electroconvulsive therapy at two and four weeks after the start of treatment in patients with depression. Substantial recovery from depressive illness occurred in both the treatment and placebo groups, but by the time the differences between the two groups had disappeared all patients were
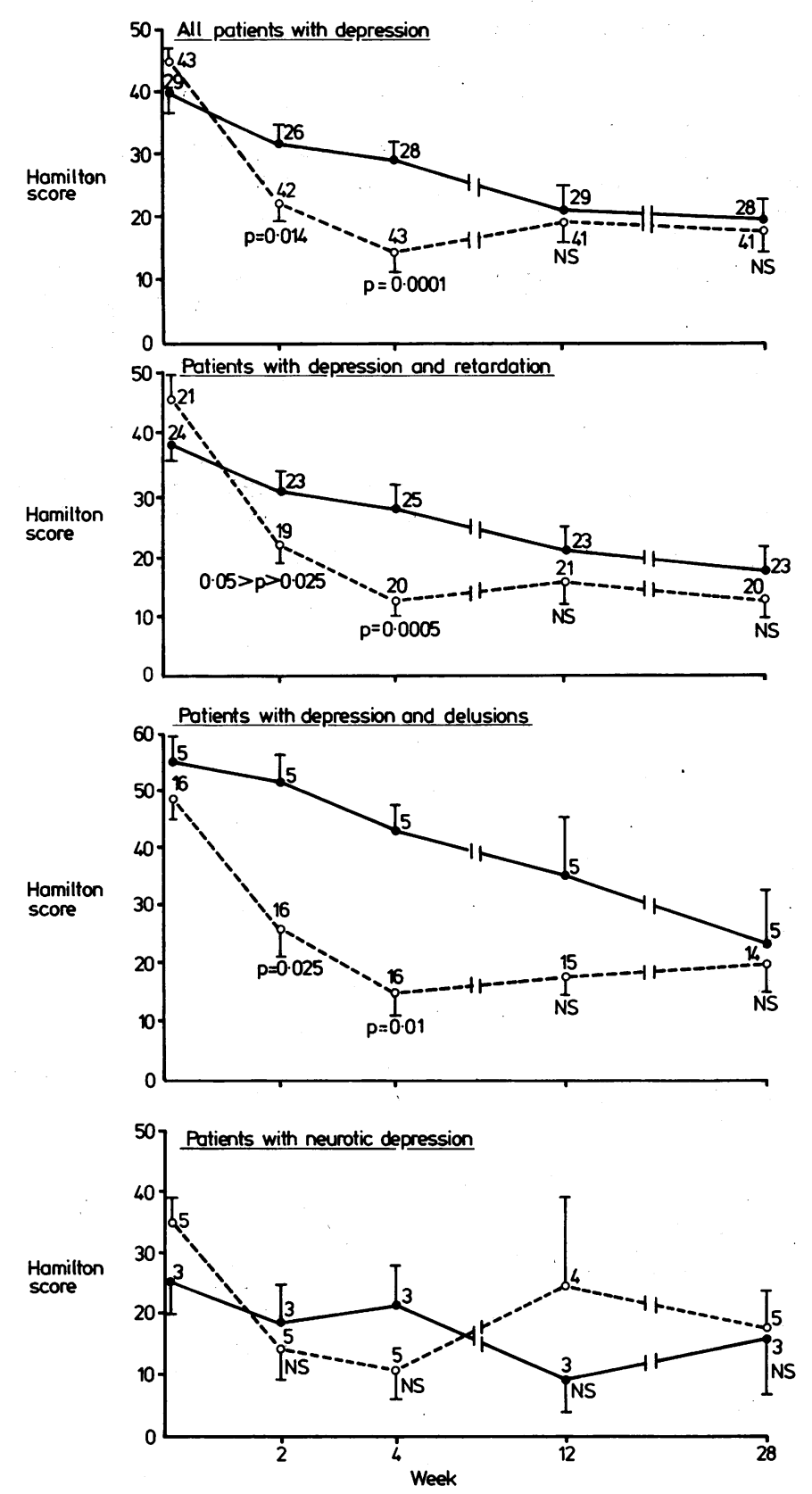

Mean (SE) Hamilton scores in patients according to category of depression and whether they received real or simulated electroconvulsive therapy. (Significance assessed by analysis of variance.)

receiving a variety of treatments regarded as appropriate by their psychiatrist. Thus progress in the two groups was only comparable during the first four weeks of the trial. When the results were analysed for each category of depression the outcome in favour of real electroconvulsive therapy held true for the patients with retarded depression and those with depressive psychosis. In the patients with neurotic depression there was no significant difference between the treatment and control groups, but with the small numbers of patients in this group a categorical statement of the efficacy of electroconvulsive therapy is not possible.

Those of our patients in categories of retarded depression and depressive psychosis appeared to be broadly similar in diagnostic terms to the patients admitted to the Northwick Park trial. Although in that trial a significant difference was reported between the treatment and control groups on completion of eight trial treatments, it was suggested that "the effects of repeated electrically induced convulsions are of relatively short duration ... many depressive illnesses although severe may have a favourable outcome with intensive nursing and medical care even if 
physical treatments hitherto considered to have a specific antidepressant action are not given."4

Our study was conducted on clinically selected patients from a fixed catchment area. Retrospective analysis of the rate of prescription of electroconvulsive therapy showed no alteration during the trial. The difference in outcome in favour of real treatment at both two and four weeks was greater in our study than in the Northwick Park trial. In our trial both the group of patients with depression and delusions and the group with depression and retardation were clearly responsive to electroconvulsive therapy, whereas in the Northwick Park study only the group with delusions showed unequivocal benefit. The group given placebo treatment had achieved a degree of recovery at six months comparable with that of the treatment group, but the recovery was considerably slower. Both treatment groups received a wide variety of treatments after the four weeks of the trial.

We believe that our data indicate that electroconvulsive therapy is an effective and rapidly acting treatment for severe depressive illness and that its use should be favoured in patients at risk of suicide because of the rapidity of response.

We thank the patients, relatives, nurses, and doctors of Leicestershire, whose cooperation and forbearance made this study possible. A particular debt of gratitude is due to the nurses and anaesthetists in the treatment centres and to the ward staff, who had to tolerate an additional uncertainty in caring for seriously ill patients. Financial assistance from the Trent regional research committee and the cooperation of the Leicestershire District Health Authority enabled us to employ PN and SW-E during the study.

\section{References}

1 Royal College of Psychiatrists. Memorandum on the use of electroconvulsive therapy. Br $\mathcal{F}$ Psychiatry 1977;131:261-72.

${ }^{2}$ Lambourn J, Gill D. A controlled comparison of simulated and real ECT Br $\mathcal{F}$ Psychiatry 1978;133:514-9.

${ }^{3}$ Freeman CPL, Basson JV, Crighton A. Double blind controlled trial of electroconvulsive therapy (ECT) and simulated ECT in depressive illness. Lancet 1978; $: 738-40$.

4 Johnstone EC, Deakin JFW, Lawler P, et al. The Northwick Park ECT trial. Lancet 1980 ;ii:1317-20.

5 West ED. Electroconvulsive therapy in depression: a double blind controlled trial. $\mathrm{Br} \mathrm{Med} \mathcal{F} 1981 ; 282: 355-7$.

${ }^{6}$ Ackner B, Harris A, Oldham AJ. Insulin treatment in schizophrenia: controlled study. Lancet 1957 ;i:607-11.

7 Wing JK, Cooper JE, Sartorius N. Measurement and classification of psychiatric syndromes. Cambridge: Cambridge University Press, 1974.

${ }^{8}$ Asberg M, Montgomery S, Peris C, Schalling D, Sedvall G. A comprehensive psychopathological rating scale. Acta Psychiatr Scand [Suppl] 1978;271:5-27.

Montgomery SA, Montgomery MA. A new depression scale designed to be sensitive to change. Br $\mathcal{F}$ Psychiatry 1979;134:382-9.

${ }^{10}$ Hamilton M. A rating scale for depression. $\mathcal{F}$ Neurol, Neurosurg Psychiatry 1960;23:56-62.

"Carney MWL, Roth M, Garside RF. The diagnosis of depressive syndromes and the prediction of ECT response. $B r \mathcal{F}$ Psychiatry 1965 ;iii : 659-74.

${ }^{12}$ Aitken RCB. Measures of feelings using visual analogue scales. Proceedings of the Royal Society of Medicine $1969 ; 62: 989-93$.

13 Snaith RP, Constantopoulos M, Jardine MY, McGuffin P. A clinical scale for self-assessment of irritability. Br $\mathcal{F}$ Psychiatry 1978;132:162-71.

${ }_{14}$ Spielberger CD, Gorsuch RL, Lushene R. State-trait anxiety inventory. Palo Alto, California: Consulting Psychologists Press, 1970.

(Accepted 6 October 1983)
It has been stated that there is an increased incidence of infertility in women who had perforated appendicitis in childhood. ${ }^{12}$ On close examination, however, the published data on perforated appendix and infertility do not include sufficient evidence to prove that infertility was a consequence of perforated appendicitis in most patients. We studied fertility in a group of women who as children had been operated on for perforated appendicitis.

\section{Subjects, methods, and results}

Between 1957 and 1970134 girls under 13 years of age underwent appendicectomy for perforated appendicitis at Our Lady's Hospital for Sick Children, Dublin. We succeeded in tracing $103(77 \%)$ of them, of whom 59 were married. Their ages at follow up ranged from 21 to 39 years. We studied the 59 married women.

Age at appendicectomy had ranged from $1 \frac{1}{2}$ to 13 (mean 9.1) years. The operative findings had included generalised peritonitis in 17, localised peritonitis in 29, pelvic peritonitis in six, and appendix abscess in seven.
Drains had been used in seven patients. All had been given antibiotics after operation, and 11 had developed pelvic abscesses postoperatively. Fifty had had one or more children. (Two unmarried women also had children.) There had been two cases of ectopic pregnancy, five of miscarriage, and one of hydatiform mole in the 50 fertile women.

We studied in detail the nine women who were married but without children (table). Five had been married not more than one year: three were taking family planning precautions, and two desired pregnancy but had not yet conceived. The sixth patient, who had been married for two years, had miscarried seven months after marriage, indicating that she was able to conceive. The seventh patient, who had been married for two and a half years, answered the questionnaire but did not cooperate thereafter. The remaining two patients were investigated for infertility. The first had been married for eight and a half years. She had had four operations for subacute intestinal obstruction. A tubal patency test showed the tubes to be patent. Laparoscopy was not performed in view of peritoneal adhesions. Her husband was found to have a sperm count of less than one million. The other patient had been married for 10 years. Her husband had a sperm count of nine million. In view of the diagnosis of male sterility a tubal patency test and laparoscopy were not performed.

\section{Comment}

The belief that perforated appendicitis is associated with an increased infertility rate has been based on a few reports that do no

Findings in nine childless married women 131-24 years after undergoing appendicectomy

\begin{tabular}{|c|c|c|c|c|c|}
\hline Case & $\begin{array}{c}\text { Age at } \\
\text { appendicectomy } \\
\text { (years) }\end{array}$ & $\begin{array}{c}\text { Age at } \\
\text { follow up } \\
\text { (years) }\end{array}$ & $\begin{array}{c}\text { Duration of } \\
\text { marriage }\end{array}$ & $\begin{array}{l}\text { Postoperative } \\
\text { intraperitoneal } \\
\text { abscesses }\end{array}$ & Remarks \\
\hline $\begin{array}{l}1 \\
2 \\
3 \\
4 \\
5 \\
6 \\
7 \\
8 \\
9\end{array}$ & $\begin{array}{c}8 \\
9 \\
7 \\
2 \frac{1}{2} \\
8 \frac{1}{2} \\
12 \frac{1}{2} \\
8 \\
11 \\
9 \frac{1}{2}\end{array}$ & $\begin{array}{l}21 ! \\
25 \\
30 \\
21 \\
23 ! \\
30 \\
22 ! \\
31 \\
33 !\end{array}$ & $\begin{array}{l}6 \text { months } \\
8 \text { months } \\
8 \text { months } \\
10 \text { months } \\
1 \text { year } \\
2 \text { years } \\
2 \text { ? years } \\
8 \text { ? years } \\
10 \text { years }\end{array}$ & $\begin{array}{l}\text { Pelvic abscess } \\
\text { Pelvic abscess } \\
\text { Pelvic abscess } \\
\text { Intra-abdominal abscess }\end{array}$ & $\begin{array}{l}\text { Taking contraceptive pill } \\
\text { Not taking family planning precautions } \\
\text { Taking contraceptive pill } \\
\text { Taking contraceptive pill } \\
\text { Not taking family planning precautions } \\
\text { Miscarriage } 7 \text { months after marriage } \\
\text { Uncooperative } \\
\text { Husband sterile } \\
\text { Husband sterile }\end{array}$ \\
\hline
\end{tabular}

